\title{
Anti-Diabetic Potential of Methanol Extract of Cooked Corn Silk (Stigma Maydis) on Alloxan-Induced Diabetes in Albino Mice
}

\author{
Umar Muhd Sani* \\ Department of Chemistry, Nigeria Police Academy, Wudil, Kano State, Nigeria
}

*Corresponding author: Sani UM, Organic Chemistry Unit, Department of Chemistry, Kaduna State University, Kaduna, Nigeria, E-mail: usindabawa@yahoo.com

Citation: Sani UM (2016) Anti-Diabetic Potential Of Methanol Extract Of Cooked Corn Silk (Stigma Maydis) On AlloxanInduced Diabetes In Albino Mice. J Pharma Pharma Sci, JPPS:105. DOI:10.29011/2574-7711/100005

Received Date: 04 October, 2016; Accepted Date: 22 November, 2016; Published Date: 28 November, 2016

\begin{abstract}
The use of herbal remedies, including corn silk, classified as Stigma or Zea mays are popular as an alternative to standard Western allopathic medicine for a variety of problems, including prostate disorders, a diuretic as well as for bedwetting and obesity. In the present study the ant diabetic potential of methanol extract of cooked, dried and pulverized Stigma was assessed in alloxan-induced diabetic albino mice. Hyperglycemia induced by the injection of $150 \mathrm{mg} /$ $\mathrm{kg}$ (i.p.) of alloxan monohydrate freshly dissolved in physiological saline. Doses $(250,500$ and $750 \mathrm{mg} / \mathrm{kg}$ ) per os, of the extract were separately administered to three groups of five diabetic mice each in the study. The activity compared with reference standard glibenclamide $(2 \mathrm{mg} / \mathrm{kg}$, p.o.) and negative control of physiological saline. Treatment of the alloxan-induced diabetic mice with the methanol extract of Stigma decreased the raised blood glucose levels in a dosedependent manner. The methanol extract exhibited relatively significant $(\mathrm{P}<0.05)$ anti-diabetic effect after $72 \mathrm{~h}$ and 96 $\mathrm{h}$ of treatment with the doses of 500 and $750 \mathrm{mg} / \mathrm{kg}$ body weight, respectively. Results of photochemical screening of the methanol extract of cooked Stigma have indicated the presence of cardiac glycoside, steroids, terpenoids, alkaloids, flavonoids, carbohydrates and anthraquinones.
\end{abstract}

\section{Objective of the Study}

All studies done on the anti-diabetic activity of corn silks did not include cooked corn silk. Of course, therefore, some photochemical may be lost into the boiling water while cooking corn silks. This may or may not include corn silk polysaccharides which were reported to be ant diabetic [1] therefore interested in finding out the effect of boiling the corn silk. I don't know whether this is not a drive to carrying out a research.

Keywords: Alloxan Monohydrate; Cooked Corn Silk; Diabetes Mellitus; Physiological Saline; Glibenclamide; Albino Mice

\section{Introduction}

Corn silks are scientifically referred to as Maydis stigma or Zea mays. There are five species of zeagenus, which are Z. diploperennis, Z. luxurians, Z. nicaraguensis, Z. parennisand Z. mays
L. [2]. However, Z. mays subspecies is the only cultivated species while the other species and subspecies are wild grasses. Zea Mays is simply called maize or corn. As a monoecious plant, corn produces both male and female flowers. The corn silk that grows out of the ear is the female part of a corn plant while the male part of the plant is the tassel growing out the top of the corn stalk. The corn silk is the stigma and style of the female part of the corn. The stigma is the sticky end of the silk where pollen attaches and the style is the tube from the stigma to the ovary, where the kernel forms on the cob. Corn silk elongates beyond the cob covering the edible part of the plant. The silks are fine, soft, relatively long (10$20 \mathrm{~cm}$ ) with a mild sweetish taste and look like a tuft of hairs [3]. The color of the corn silks, at first are usually light green and later turn into red, yellow or light brown Zea mays are used as either a food, as animal feed or as industrial raw material. In developing countries like Nigeria maize is mainly used as a staple food whereas more than 60 percent of it is used as animal feed in the de- 


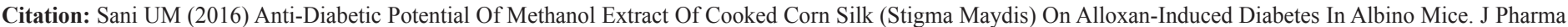
Pharma Sci, JPPS:105.

veloped countries. Corn silk as an herb has been reported to have properties of antioxidant, anti-prostitutes and antispasmodic [4] In addition, corn silk is well known in treating infection and cystitis [5], kidney stone and other renal illness [6]. One study, however, has shown that corn silk has no antibacterial activity when investigated against many bacterial species [7]. Based on folk remedies, corn silk has been used as an oral ant diabetic agent in China for decades. A part from the ant diabetic use, corn silk is also used as a diuretic and a decoction of the silk is taken for the treatment of urinary troubles and gallstones [8]. In fact, although not scientifically proven, corn silk tea has been claimed to have so many health benefits to human such as lowering blood pressure, decrease prostate inflammation, diabetic and urinary tract infection, edema, obesity and promote relaxation [9]. However, in spite of its widespread use, the mechanisms underlying hypoglycemic activity of corn silk not yet understood [10]. With regards to toxicity, a study using male and female Westar rats has confirmed that corn silk is non-toxic in nature [11]. The intake of corn silk as such has also been reported to have no adverse effects [12] and this supports the safety of corn silk for human consumption and its use as an herbal drug for healthcare applications.

\section{Mechanism of action}

Glibenclamide simply works mainly by stimulating $\beta$-cells of the pancreas to produce more insulin. With chronic administration of glibenclamide the blood glucose lowering effect persists despite a gradual decline in the insulin secretary response to the drug. This may explain also why the decrease in blood glucose level in my research prolonged.

\section{Metabolism of glibenclamide in the liver}

Glibenclamide has a short plasma half-life (2-10 hrs) but prolonged biological effect due to the formation of active metabolites! Generally, sulphonylureas (glibenclamide inclusive) cause hypoglycemia (as a side effect). Glibenclamide metabolites (3-cishydroxyglibenclamide and 4-trans-hydroxyglibenclamide - where the cyclohexyl ring is hydroxylated at positions 3 and 4, respectively) exert some hypoglycemic effect that contributes to the prolonged decrease in blood glucose levels in test animals. Retention of 4-trans-hydroxyglibenclamide prolongs the hypoglycemic effect of the agent in those with severe renal impairment. Clearance may therefore be substantially decreased in those with severe renal impairment. However, I did not carry out renal impairment test on the test animals.

\section{Materials and methods}

Plant material Maize or corn purchased in Wudil local market, Wudil Local Government area, Kano state, Nigeria. Locally maize is roasted or cooked and the seeds removed from the cobs and eaten using teeth. Before roasting, both the husks and silks have to be removed. The whole maize containing the husks and silks are usually cooked in pure water. In this study the cooked maize used and after the cooking done the silks, mostly attached in between the rows of the seeds, were removed, air dried for four weeks and pulverized to coarse powder using pestle and mortar. The powdered material (dark brown) kept in an airtight and dried white polyethene bag.

\section{Sample extraction}

$1 \mathrm{~kg}$ of the corn silk powder divided into 2 portions of $500 \mathrm{~g}$ each and macerated with distilled methanol $(2.0 \mathrm{~L})$ at room temperature in maceration bottles. The maceration bottles were occasionally shaken for three days to obtain a reasonable amount of extract and then decanted and filtered using filter paper. Fresh solvent $(1.5 \mathrm{~L})$ added to the remains in the two bottles and the bottles occasionally shaken for two days. The extracts were decanted and again filtered into the previous filtered extracts. The filtrates of the two extracts of each portion were combined and concentrated using rotary evaporator to obtain a methanol extract (brownish-black paste) and the solvent recovered.

\section{Photochemical screening}

Photochemical screening carried out on the methanol extract of corn silk using standard procedures and tests to determine the presence of alkaloids, flavonoids, anthraquinones, steroids, terpenoids, tannins, cardiac glycosides, reducing sugars and saponins.

\section{Pharmacological study}

\section{Animals}

All experimental animals used were male and female albino mice (weighing between 24-33g and were obtained from Nigerian Institute for Tripanosomiasis Research (NITR), Kaduna State, Nigeria. The mice were kept in clean and dry aluminium cages under standard environmental conditions and were fed using growers marsh feed and given water ad libitum. The mice were fasted, however, for 12 hours before experimentation. The experimental methods involving animals have been approved by Animal Research Ethics Committee of Kaduna State University, Kaduna-Nigeria.

\section{Experimental design}

Diabetes induced by a single intraperitoneal injection of $150 \mathrm{mg} / \mathrm{kg}$ body weight alloxan monohydrate freshly dissolved in regular saline $0.9 \%$ physiological saline immediately before used to overnight fasted albino mice (free access to water allowed). Seven days after, animals with fasting blood glucose level $\geq 7.0$ $\mathrm{mmol} / \mathrm{dL}$ (or $\geq 126 \mathrm{mg} / \mathrm{dL}$ ) or more were considered diabetic and 
Citation: Sani UM (2016) Anti-Diabetic Potential Of Methanol Extract Of Cooked Corn Silk (Stigma Maydis) On Alloxan-Induced Diabetes In Albino Mice. J Pharma Pharma Sci, JPPS: 105.

employed in the study. The diabetic mice were then grouped into 5 groups of five mice each as follows

Group I: Served as positive control and received glibenclamide $(2$ $\mathrm{ml} /$ kgbodyweight)

Group II: Received Methanol extract at $250 \mathrm{mg} / \mathrm{kg}$ bodyweight

Group III: Received Methanol extract at $500 \mathrm{mg} / \mathrm{kg}$ body weight

Group IV: Received Methanol extract at $750 \mathrm{mg} / \mathrm{kg}$ body weight

Group V: Served as negative control receiving physiological saline (10 $\mathrm{ml} / \mathrm{kg}$ body weight)

The animals were treated once and blood glucose concentrations were measured at 0, 24, 48, 72 and 96 hours. Blood samples were taken by a snip-cut at the tip of the tail and blood glucose levels were measured with a glucometer (a ONE TOUCH Ultra easy blood glucose monitoring system, Life Scan Europe Division of Cilag GmbH international 6300 Zug Switzerland).

\section{Statistical analysis and data evaluation}

All the values of blood glucose concentrations were expressed as mean \pm Standard Error Of Mean (SEM.) and analysis of variance, ANOVA, followed by Student's t-test.

\section{Protein binding}

Glibenclamide is extensively ( $\sim 99 \%)$ bound by serum proteins (and also the metabolite 4-trans-hydroxyglibenclamide is greater than $97 \%$ bound to serum proteins) and is recycled hepatic ally. Both of these factors contribute to prolonged duration of action of glibenclamide. Protein binding is primarily non-ionic making glibenclamide less likely to displace or be displaced by drugs that are ionically bound to proteins. This makes glibenclamide to rather spend more time in the system.<smiles>CCCCNC(=O)c1cc(Cl)ccc1OC</smiles>

\section{Results and Discussion}

\section{Photochemical screening}

The results of photochemical studies on the methanol extract of cooked corn silk have been provided in (Table 1)

\begin{tabular}{|c|c|}
\hline Photochemical & Observation \\
\hline Alkaloids & + \\
\hline Saponins & + \\
\hline Steroids & + \\
\hline Flavonoids & + \\
\hline
\end{tabular}

\begin{tabular}{|c|c|}
\hline Cardiac Glycoside & + \\
\hline Tannins & + \\
\hline Anthraquinones & + \\
\hline Carbohydrates & + \\
\hline Key $:+=$ & positive \\
\hline
\end{tabular}

Table 1: Photochemical analysis of the extract of cooked Allium cepa.

\section{Pharmacological study}

The effects of the methanol extracts of the cooked corn silk on fasting blood glucose levels in alloxan monohydrate-induced diabetic albino mice have been given in (Table 2) 
Citation: Sani UM (2016) Anti-Diabetic Potential Of Methanol Extract Of Cooked Corn Silk (Stigma Maydis) On Alloxan-Induced Diabetes In Albino Mice. J Pharma Pharma Sci, JPPS:105.

\begin{tabular}{|c|c|c|c|c|c|c|}
\hline \multirow{2}{*}{ Test material } & \multirow{2}{*}{ Groups } & \multicolumn{5}{|c|}{ Blood glucose levels in $(\mathrm{mmol} / \mathrm{L})$ sampling time in hours } \\
\hline & & 0 & 24 & 48 & 72 & 96 \\
\hline Glibenclamide (positive control) & Group I & $11.5 \pm 1.9$ & $8.3 \pm 2.0$ & $6.5 \pm 2.4$ & $5.4 \pm 3.7$ & $4.1 \pm 2.1$ \\
\hline $250 \mathrm{mg} / \mathrm{kg}$ & Group II & $11.1 \pm 3.5$ & $10.1 \pm 2.5$ & $9.8 \pm 3.0$ & $9.3 \pm 2.7$ & $8.7 \pm 3.2$ \\
\hline $500 \mathrm{mg} / \mathrm{kg}$ & Group III & $9.8 \pm 2.1$ & $9.2 \pm 1.3$ & $8.8 \pm 1.4$ & $7.4 \pm 2.2$ & $6.5 \pm 1.1$ \\
\hline $750 \mathrm{mg} / \mathrm{kg}$ & Group IV & $10.4 \pm 1.7$ & $9.3 \pm 2.3$ & $8.6 \pm 0.8$ & $6.5 \pm 2.1$ & $5.4 \pm 2.5$ \\
\hline Physiological sane (negative control) & Group V & $10.5 \pm 1.3$ & $10.7 \pm 3.0$ & $9.2 \pm 2.1$ & $10.6 \pm 1.5$ & $11.2 \pm 1.5$ \\
\hline
\end{tabular}

Table 2: Antidiabetic effect of methanol extracts of cooked Allium cepa in alloxan- induced diabetic mice.

The results of photochemical screening of the methanol extract of cooked corn silk have shown the presence of alkaloids, saponins, steroids, flavonoids, terpenoids, cardiac glycosides, tannins, anthraquinones and carbohydrates. Corn silk reported to be rich in phenolic compounds, particularly flavonoids $[6,13]$. Another photochemical screening of various extracts of sweet corn silk has shown positive results for flavonoids, alkaloids, phenols, steroids, glycosides, carbohydrates, terpenoids, anthraquinones and tannins [14]. The results of these studies also correlate well with the report given by [15]. The potential medicinal uses of corn silk are related to its pharmacologically active photochemical. The ant diabetic activities of the graded extracts tested in this study could therefore be attributed to the photochemical found in the extract, some of which have been reported to be hyperglycemic by many researchers. For example, flavonoids and tannins have been known to possess ant diabetic activity [16] and in other study flavonoids, sterols, terpenoids, alkaloids, saponins and phenolics have been reported to be ant diabetic principles [17]. A study conducted on Moringa Oleifera Leaves reported that the presence of flavonoids, terpenoids, tannins and saponins explains why the plant is used for treating diabetes $[16,18]$. These secondary metabolites are used ethno-pharmacologically to treat diabetes and hyperglycemia [19]. Two anthraquinones have been isolated from the ethanol extract of rhubarb rhizome and indicated to have anti-diabetic properties [21]. Alkaloids have also been implicated to have hypoglycemic activity and it found that the neem seed kernel powder contained hypoglycemic alkaloids that lowered blood sugar levels in alloxaninduced diabetic rabbits [22]. Results of a study on the polysaccharides isolated from corn silk have shown that $100-500 \mathrm{mg} / \mathrm{kg}$ body wt. of the polysaccharides decreased the blood glucose levels and improved the glucose tolerance of streptozotocin (STZ) - induced diabetic rats [1]. This indicated that the corn silk polysaccharides may be useful as an anti-diabetic agent.

The presence of flavonoids in corn silk has already been reported and the pharmacological activities of corn silk also much related to the flavonoids. Flavonoids are a widely distributed group of plant phenolic compounds which are effective as antioxidants [23]. A recent study showed that the total flavonoids content of the butanol extract of corn silk is in good correlation with the total phenolic content [13]. More recently five different flavonoids as well as some falconoid derivatives have been identified in corn silk [11]. The isolated flavonoids from corn silk were found to act as anti- fatigue and ant diabetic agents [23] and the phenolics and flavonoids were thought to give corn silk its antioxidant properties [24].

The aqueous extract of corn silk has been found to reduce hyperglycemia and use can be made of it as a hypoglycemic food for diabetic patients [25]. In another study the effect of corn silk aqueous extract on glycemic metabolism using an alloxan-induced hyperglycemia in mice, with Xiaoke pills (a Chinese diabetic medicine) as positive control and saline as negative control, revealed that the blood glucose levels of the Xiaoke pill and extract treated groups decreased appreciably [9]. In the present studies comparison of the values of blood glucose levels in the treated and the control groups of alloxan-induced diabetic mice suggested some favourable ant diabetic effect of the cooked corn silks. Statistical analysis using student's t-test revealed that there is a statistically valid difference between the treated and the control groups [26]. The methanol extract exhibited relatively significant $(\mathrm{P}<0.05)$ anti-diabetic effect at $72 \mathrm{~h}$ and $96 \mathrm{~h}$ at the doses of 500 and $750 \mathrm{mg} /$ $\mathrm{kg}$ body weight, respectively. From the results it can be suggested that the methanol extract exhibited dose dependent action in a similar mechanism as glibenclamide i.e., by stimulation of surviving $\beta$-cells to release more insulin [27].

\section{Conclusion}

The aqueous extract of corn silk has already been investigated and found to reduce hyperglycemia. In the present studies comparison of the values of blood glucose levels in the treated 
Citation: Sani UM (2016) Anti-Diabetic Potential Of Methanol Extract Of Cooked Corn Silk (Stigma Maydis) On Alloxan-Induced Diabetes In Albino Mice. J Pharma Pharma Sci, JPPS: 105.

and the control groups of alloxan-induced diabetic mice suggested some favourable ant diabetic effect of the cooked corn silks even though, while cooking, some photochemical may be lost into the boiling water. The experimental results have illustrated that the methanol extract of the cooked corn silk exhibited dose dependent action in a similar mechanism as glibenclamide where surviving beta cells are stimulated to release more insulin.

\section{Reference}

1. Zhao W, Yin Y, Yu Z, Liu J, Chen F (2012) Comparison of anti-diabetic effects of polysaccharides from corn silk on normal and hyperglycemia rats. Int. J. Biol. Macromol 50: 1133-1137.

2. Wan Rosli, Wan Ishak, Solihah Mat Ali (2016) Assessment of Malaysian Corn silk Bioactive Compounds and Its Cytotoxicity test on Brine Shrimp (Artemia salina), Health and the Environment Journal 7: 124138.

3. Wan Rosli WI, Jesmine K, Mohsin SSJ, Ng SH, Farid CG (2007) Highresolution morphological characterization and micro-minerals composition of corn silk (Zea maysll-Maydis stigma), Proceedings of International conference on chemical sciences.

4. Buhner SH (2007) the natural testosterone plan; for sexual health and energy 77-78.

5. Steenkamp V (2003) Phytomedicine for the prostate. Fitoterapia 74: 545-552.

6. Maksimovic Z, Dobric S, Kovacevic N, Milovanovic Z (2004) Diuretic activity of Maydis stigma extract in rats. Pharmazie 59: 193-197.

7. Alam EA (2011) Evaluation of antioxidant and antibacterial activities of Egyptian Maydis stigma (Zea mays hairs) rich in some bioactive constituents. J. Am. Sci 7: 726-729.

8. Bamidele V, Owoyele, Negedu M, Onasanwo SA, Oguntoye SO (2010) Analgesic and Anti-inflammatory effects of aqueous extract of Zea mays husk in male wistar rats. J. Med Food 13: 343-347.

9. Khairunnisa H, Puziah H, Shuhaimi M (2012) Corn Silk (Stigma Maydis) in Healthcare: A Photochemical and Pharmacological Review, Molecules 17: 9697-9715.

10. Mathew FO, Elizabeth MB (2016) Corn Silk Extracts as Scavenging Antioxidant in Oxidative Stress Induced Rabbits Using Corticosterone. Am. J. Biomed. Sci 8: 38-45.

11. Wang C, Zhang T, Liu S, Zhang C, Wang E (2011) Sub chronic toxicity study of corn silk with rats. Journal of Ethno pharmacology 137: 36-43.

12. Josephine MGV, Induja TA, Jony B, Manoj J, Shivasamy MS (2015) Recent trends in effective utilization of by-product of corn, Indian Journal of Science 22: 18-26.
13. Liu J, Lin S, Wang Z, Wang C, Wang E, et al. (2011) Supercritical fluid extraction of flavonoids from Maydis stigma and its nitrite-scavenging ability. Food Bioprod. Process 89: 333-339.

14. Thoudam B, Ramya J, Usha K (2012) Effect of Methanolic Extract of Sweet Corn Silk on Experimentally Induced Hyperthyroidism in Swiss albino rats, IRJP 3: 241-245.

15. Devleen K, Divneet K, Navpreet K, Anuja C, Poonam A (2015) Corn silk: A Review on Botanical and Pharmacological Considerations, European Journal of Biomedical and Pharmaceutical sciences 2: 554-572.

16. Sharma VK, Kumar S, Patel HJ, Hugar S (2010) hypoglycemic activity of Ficus glomerata in alloxan induced diabetic rats, International Journal of Pharmaceutical Sciences Review and Research 1: 18-22.

17. Tiwari AK, Madhusudana RJ (2002) Diabetes mellitus and multiple therapeutic approaches of Photochemical: present status and future prospects. Current science 83: 30-38.

18. Fahey JW (2005) Moringa oleifera: A Review of the medical evidence for its nutritional, therapeutic and prophylactic properties. Trees Life Journal 15: 1-15.

19. Krishnaiah D, Devi T, Bono A, Sarbatly R (2009) Studies on photochemical constituents of six Malaysian medical plants. Journal of Medicinal Plant Research 3: 67-72.

20. Lee MS, Sohn CB (2008) Anti-diabetic properties of chrysophanol and its glucoside from rhubarb rhizome, Biol Pharm Bull 31: 2154-2157.

21. Bobanna KN, Kannan J, Gadgil S, Balaraman R, Rathod SP (1997) Antidiabetic and antihyperlipaemic effects of neem seed kernel powder on alloxan diabetic rabbits. Ind J Pharmacol 29: 162-167.

22. Pietta PG (2000) Flavonoids as antioxidants, J. Nat. Prod 63: 10351042.

23. Hu QL, Zhang LJ, Li YN, Ding YJ, Li FL (2010) Purification and ant fatigue activity of flavonoids from corn silk. International Journal of Physical Sciences 5: 321 - 326.

24. Ebrahimzadeh MA, Pourmorad F, Hafe S (2008) Antioxidant Activities of Iranian Corn Silk. Turkish Journal of Biology 32: 43-49.

25. Guo J, Liu T, Han L, Liu Y (2009) the effects of corn silk on glycaemic metabolism. Nutr. Metab 6: 47.

26. Bushman BS (2002) the genetic basis of chlorogenic acid synthesis in maize. PhD dissertation, University of Missouri-Columbia, Missouri United States.

27. Ivorra MD, Paya M, Villar A (1988) Hypoglycemic and insulin release effects of tormentic acid: A new hypoglycemic natural product. Planta Med 54: 282-285. 